\title{
Lever-pressing behavior in three species of kangaroo rats'
}

FREDERICK J. BREMNER

TRINITY UNIVERSITY, SAN ANTONIO, TEXAS

Three species of kangaroo rats were conditioned under three schedules of reinforcement; continuous, S-D 10 and S-delta 30 , and fixed interval $3 \mathrm{~min}$. All three species of kangaroo rats tested gave scalloped cumulative records during continuous reinforcement, S-D 10 and S-delta 30 but smooth, negatively accelerated records during fixed interval schedules. This is directly opposite to the cumulative records usually obtained from the laboratory rat under these schedules.

When working with a species whose behavior has not previously been explored in the laboratory, it is necessary to define the variables which control its behavior. The effectiveness of stimulus events employed in the conditioning paradigm have not been explored for the kangaroo rat (Dipodomys). Therefore a study was undertaken to determine what stimuli might act as cues for behavior (CS) and what stimuli might be capable of reinforcing behavior (UCS). This was done by first defining a manipulatable response (R) and using that as a basis of operationally defining the stimulus variables. After defining the stimulus and $\mathbf{R}$ variables the laws of reinforcement contingencies were explored to determine if they would obtain for this unstudied species of animal. In short, the present study is directed toward defining the stimulus variables and examining some of the laws of reinforcement when applied to the kangaroo rat.

\section{Subjects and Apparatus}

Fifteen kangaroo rats of three species (Dipodomys panamintinus, Dipodomys merriami, Dipodomys deserti) were used in the present study. These Ss were instrumentally conditioned in a standard Foringer Skinner box, which was controlled by Foringer programming modules. Each lever press delivered six small millet seeds to the food hopper. The box was modified by the addition of 1/4-in. hardware cloth over the grid floor so that the Ss could not catch their legs between the bars of the grid floor.

\section{Procedure}

All 15 Ss were given at least one $15-h$ session on continuous reinforcement (CRF). The CRF sessions were conducted by placing the Ss in the Skinner box in the evening, turning on the programmer, and leaving the animal to its own devices. The animal was removed the following morning and returned to its home cage. Most animals learned in only one session, although some required a second session. The animals in the first training session were $24-\mathrm{h}$ deprived.
After the first training session however, the Ss were only $9 \mathrm{~h}$ deprived. Since the Ss have cheek pouches it is difficult to determine when they last ate.

Following the initial training, $10 \mathrm{Ss}$ were tested on CRF to obtain stable rates. A group of $10 \mathrm{Ss}$ were also trained on a "light on" (S-D 10-sec) "light off" (S-delta $30 \mathrm{sec}$ ) schedule until $75 \%$ of their $\mathbf{R}^{\prime}$ 's occurred during the S-D period. Finally, four Ss were tested under a 3-min fixed interval schedule (FI 3). No effort was made to use Ss of exactly the same experience in later treatments except that all Ss had had at least one 15-h CRF session in which they had performed well. The animals obtained all their food in the experimental situation. They were, however, given lettuce once every two weeks. The effect of lettuce on those animals is reported elsewhere (Clark \& Bremner, 1967).

\section{Resulfs and Discussion}

Observations in our laboratory showed that the Dipodomys would approach and take millet seeds directly from the E's hand. These observations suggested that grain was a reinforcer (i.e., an event which when placed in close temporal contiguity following a response increased the probability of that $R$ ). To test whether millet seed would serve as a reinforcer to Dipodomys for lever pressing, several animals were tested one at a time in the Skinner box. It was found that these Ss would readily learn to press for a millet seed reward. This, in effect, established that millet was a reinforcer by demonstrating its transsituational character. That is, the circularity in defining a reinforcer was avoided since millet would reinforce approach behavior (a $R$ already in the Ss' repertory) and also, lever pressing behavior (a $R$ not previously in the Ss' repertory) and that this was true of the 10 Ss tested.

Next, it was necessary to define a manipulatable CS. Although the lever in a lever press situation is itself a CS, it is rather nebulous and most investigators prefer a CS more directly under their control. To implement this, the S-D 10-S-delta 30 schedule was used. The performance of all $10 \mathrm{Ss}$ was brought to a previously determined criterion of $75 \%$ Rs during S-D under this regimen. The above results provided a definition of stimulus and response variables. In short, the CS was defined as a light on for $10 \mathrm{sec}$, the conditioned $\mathbf{R}$ as a lever press, the UCS as presentation of six millet seeds, and the unconditioned $\mathbf{R}$ as the picking up of the millet. However, the cumulative 
records obtained under this regimen of reinforcement showed a curious form. Figure 1 shows that these records are scalloped.

The figure shows extended flat spots followed by sharp inclines. The inclines represent high rates of pressing while the plateaus represent periods of no lever pressing. Moreover, the scalloping of the cumulative record did not correlate with the reinforcement schedule; since the Ss were on a discrimination schedule of S-D 10-S-delta 30 , the recycling time was 40 sec regardless of the $S^{\prime} R$, but the Ss were responding as though they were on a long fixed interval schedule of 10 to $15 \mathrm{~min}$. These data raised questions concerning the parameters of reinforcement operating since the Ss were performing on a schedule of reinforcement which was less rewarding than the one programmed by the E. Examination of the data presented in Fig. 1 made it clear that it was not the level of discrimination that was the critical factor because even though S 014 was discriminating well (90\% Rs during S-D) while S 002 was discriminating poorly (less than $50 \%$ Rs during S-D), they both show the same type of cumulative record. The form of the data presented in Fig. 1 are typical of all Ss tested regardless of species or previous experience.

Since these data raised questions concerning reinforcement parameters, four Ss were tested on a fixed interval schedule of $3 \mathrm{~min}$, to determine if the typical scalloped cumulative record would occur. The record obtained from $S$ number 003 under this regimen is presented in Fig. 2. By way of comparison, Fig. 2 contains a record taken during CRF for this animal. It can readily be seen from inspection of this figure that kangaroo rats perform just the opposite to laboratory rats, giving a scalloped curve during CRF whereas the laboratory rat gives a scalloped record during FI 3 (Ferster \& Skinner, 1957).

Knowledge of the morphology of these animals, coupled with simple observation revealed an answer to this paradox. The Dipodomys have cheek pouches

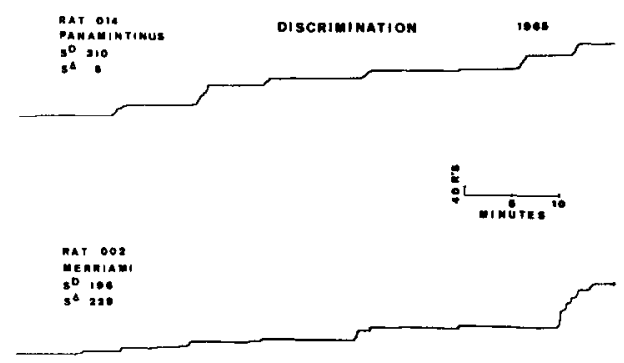

Fig. 1. Cumulative record of two Ss showing scalloped form.

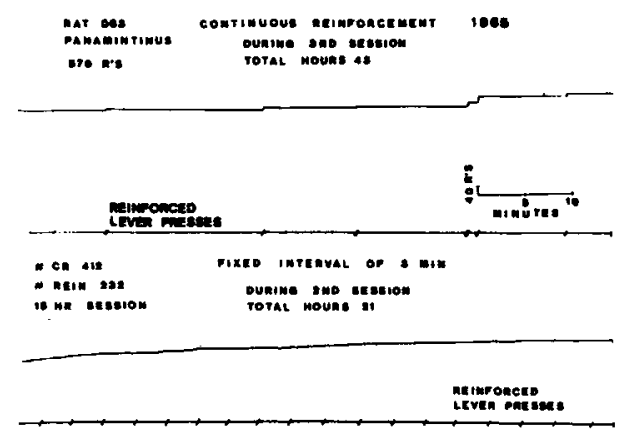

Fig. 2. Two cumulative records for one $S$. The top record describes performance during CRF while the bottom record describes performance during FI 3 . The line under the cumulative record shows where reinforcement occurred.

which they often fill before eating, thus accounting for the rapid pressing while filling the pouches. The long flat areas were recorded while the Ss either ate the food or looked in vain for a place to store the food in a sterile Skinner box. During the FI 3 schedule, on the other hand, the Ss could receive only a few seeds at a time (six every $3 \mathrm{~min}$ ), and therefore they continued to perform in a spaced pattern until their pouches and stomachs were full. Observation of the Ss in the Skinner box conflirmed the above statements.

\section{Conclusion}

The conclusions drawn from the above data are that one must use great care when generalizing data from species to species, even when they are as closely related as the laboratory rat and the Dipodomys (both rodents), to say nothing of trying to generalize between rats and humans, particularly with regard to differences in morphology. Also, even in our highly computerized laboratories, much can still be learned from simple observations of the Ss' behavior. Finally, it is interesting to speculate on the secondary reinforcement value of the cheek pouch in the Dipodomys since it does seem to cause these animals to perform at a consistent pace even during long fixed interval schedules.

\section{References}

Clark, R. H., \& Bremner, F. J. Toward an electro-physiological identification of a primary drive factor. Psychon. Sci., 1967, 8.

Ferster, C. B., \& Skinner, B. F. Schedules of reinforcement. New York: Appleton-Century-Crofts, 1957.

\section{Note}

1. This investigation was supported in part by U. S. Public Health Service Research Grants NIMH 11970 and NIMH 11618. 